This is a self-archived version of an original article. This version may differ from the original in pagination and typographic details.

Author(s): Andres, Josh; Kari, Tuomas; von Kaenel, Juerg; Mueller, Florian Floyd

Title: Co-riding With My eBike to Get Green Lights

Year: 2019

Version: Accepted version (Final draft)

Copyright: @ 2019 ACM

Rights: In Copyright

Rights url: http://rightsstatements.org/page/InC/1.0/?language=en

Please cite the original version:

Andres, J., Kari, T., von Kaenel, J., \& Mueller, F. F. (2019). Co-riding With My eBike to Get Green Lights. In DIS 2019 : Proceedings of the 2019 on Designing Interactive Systems Conference (pp. 1251-1263). ACM. https://doi.org/10.1145/3322276.3322307 


\title{
"Co-riding With My eBike to Get Green Lights"
}

\author{
Josh Andres ${ }^{1,2}$, Tuomas Kari ${ }^{2,3}$, Juerg von Kaenel ${ }^{1}$, Florian 'Floyd' Mueller ${ }^{2}$ \\ ${ }^{1}$ IBM Research \\ Australia \\ \{josh.andres, jvk\} \\ @aul.ibm.com \\ ${ }^{2}$ Exertion Games Lab RMIT \\ University Australia \\ \{josh, tuomas, floyd \\ ${ }^{3}$ University of Jyvaskyla \\ Finland \\ @exertiongameslab.org \\ tuomas.t.kari@jyu.fi
}

\begin{abstract}
Researchers are increasingly exploring interactive technology supporting human-system partnership in an exertion context, such as cycling. So far, most investigations have supported the rider cognitively, by the system "sensing and presenting" information to assist the rider to make informed decisions. In contrast, we propose systems that promote user-system co-operation, by "sensing and acting" on information to assist the rider, not only "cognitively" but also "physically", with the aim of facilitating user-system cooperation in an exertion context. Our prototype, "Ari", is a novel augmented eBike designed to facilitate user-system co-operation, where the information that each party can sense is used in regulating the speed to cross all traffic lights on green. A study with 20 bike riders resulted in five themes and six design tactics to further the design of interactive systems at the intersection of human-computer integration in an exertion context, thereby facilitating user-system cooperation to augment the exertion experience.
\end{abstract}

\section{Author Keywords}

Human-system-partnership; exertion; eBike; cycling.

\section{CCS CONCEPTS}

- Human-centered computing $\rightarrow$ Human computer interaction $(\mathrm{HCI}) \rightarrow$ Interaction paradigms $\bullet$ Embedded and cyber-physical systems $\rightarrow$ Sensors and actuators

\section{INTRODUCTION}

eBikes (short for electric bicycles) are popular worldwide, by reason that eBikes make cycling accessible for more people due to the electrical assistance which allows riders to go further and faster than with normal bikes [17, 40]. With over 40 million sold in 2015 [17, 43], eBikes facilitate more people to reap the benefits of engaging in physical activity and the joys of cycling with others, especially in an outdoor setting [40], while supporting environmentally choices.

\footnotetext{
Permission to make digital or hard copies of all or part of this work for personal or classroom use is granted without fee provided that copies are not made or distributed for profit or commercial advantage and that copies bear this notice and the full citation on the first page. Copyrights for components of this work owned by others than ACM must be honored. Abstracting with credit is permitted. To copy otherwise, or republish, to post on servers or to redistribute to lists, requires prior specific permission and/or a fee. Request permissions from Permissions@acm.org
}

HCI research is aware of the associated benefits and technology advances, and as a result, there is more and more interactive technology for cycling emerging, for example there is now interactive systems for wayfinding [5, 10], tracking human performance as part of the "quantified-self" movement [28, 49], and studies exploring novel human-bike interactions $[3,10]$. These works appear to be designed with the premise that the eBike senses information about the ride and the rider, and then presents this to the rider who needs to interpret it to make an informed decision, hence, we refer to these systems as providing "cognitive support".

What we propose in this work is that the eBike can go beyond "sensing and presenting" to "sensing and acting", that is, not only presenting information, but autonomically acting on information to offer physical and cognitive support with the aim of facilitating co-operation with the rider to augment the exertion experience.

In this article, we introduce Ari, the eBike, an augmented eBike capable of actuating the engine and communicating via bone-conducting headphones, with the aim of cooperating with the rider to regulate the speed and cross all traffic lights on green.

To explore the design of systems that can "sense and act" as part of the exertion experience, we lean on the notion of "integrated exertion" [2]: With "integrated exertion" we refer to systems where the user is investing physical effort as part of an exertion experience while the system can act on and react to the user's actions and the environment to support the exertion experience. This intersection between humancomputer integration, where the user and computer cooperate in partnership [16], and exertion support, where the user invests physical effort [18], is an emerging area in HCI. Due to advances in technology, such as, artificial intelligence and the internet of things, is now possible for systems to sense, interpret and also act on, resulting in a new paradigm where the system does not depend on user input to generate an output [15].

We contribute to this emerging area through a novel augmented eBike that enables user-system co-operation within an exertion context. Following an explicitation interview approach [37, 48], the experiences that our prototype elicited from riders were synthesized via thematic analysis [6] into the contributions we describe next. 


\section{Contributions}

Our work makes the following contributions:

- An implementation description of our augmented eBike that is designed to enable user-system co-operation as part of the exertion experience.

- Results from a study with 20 bike riders using our prototype.

- Five design themes for researchers interested in studying systems that enable co-operation with the user as part of an exertion experience.

- Six tactics for designers interested in developing systems that co-operate with the user as part of an exertion experience.

An initial understanding of the user experience of cooperative exertion systems is presented. This is relevant to Human-System Partnership [16], and Trusting AI [41] agendas, resulting from the system automatically acting on information in the context of facilitating partnership. This work can benefit other research areas such as, Super Human Sports [46], Mixed Reality, Healthcare Rehabilitation, and the Military, due to the focus on physical exertion and technology to support it. It also benefits interactive exertion systems (eScooters, Exoskeletons, eWheelchairs [21, 38], and Segways) due to the capability offered via the engine.

\section{RELATED WORK}

We begin by highlighting the challenge with eBike riders at intersection crossings and how this work could contribute to this societal challenge. We then describe prior work that uses interactive systems to support the cycling experience "cognitively". Finally, we look to the future and describe emerging interactive systems focusing on supporting usersystem co-operative cycling.

\section{eBike Riders are More Prone to Injury}

When comparing eBikes to regular bikes, it seems that eBike riders are more prone to injury, especially at traffic light intersection crossings $[17,39]$. It appears that this is due to riders accelerating the engine to get green lights [52]. Various studies have shown that eBikes infringing traffic lights is a common problem worldwide (e.g. China, 61\% [51], United States, 70\% [27], Austria, 36\% [7], Brazil, 38\% [4], Australia 37\% [25]). eBike riders' efforts to get the green lights by accelerating, led us to investigate how eBikes may be able to assist riders to get more green lights. One way to do so, is by focusing on user-system co-operative experiences, as each of the parties is better than the other at sensing certain things. This type of co-operative experiences could facilitate the user and the system skills to work towards the same goal and may result in getting more green lights. However, limited design knowledge exists to craft cooperative systems to augment the exertion experience. Therefore, with this work we seek an initial understanding to design interactive systems that can facilitate user-system cooperation to augment the exertion experience.

\section{Supporting Cycling Cognitively}

Recently, interactive technology systems for cycling have advanced considerably, e.g. "Strava" and "Endomondo" record and compare information about the rider's performance for later analysis [49], while products like the "Cobi Bike" [5] and "Smarthalo" [9], and research work like the "Gesture bike" [10], explore using visuals to assist the user with wayfinding. These systems attempt to enhance the cycling experience "cognitively", e.g. by displaying sensed information about the user's performance or for wayfinding assistance. This can be distracting because the rider's eyesight is focused on the road ahead [42]. Furthermore, these designs are built with the premise that the system is first sensing and then presenting information to the user, who then needs to interpret what this means in order to consider how to proceed. Rather than, exploiting the opportunity for the system to participate based on sensed information to cooperate with the rider, an approach we explain next.

\section{Supporting User-System Co-operative Cycling}

Research has begun to explore supporting co-operative cycling: "The Bike Becomes the Gym" system allows the rider to set a challenge level which results in the eBike adjusting the engine's assistance according to the inclination of the road to offer a challenging exercising experience [11]. Relatedly, the "Pollution Mitigation eBike" [47] senses air quality data ahead of a planned road and acts on this by increasing the eBike's engine assistance, so that the user's breathing rate is lower when in polluted areas. Further examples include the "Heart Rate Bike" [33], which, based on the user's heart rate readings, increases the eBike's engine assistance to maintain a challenging ride. In contrast to promoting increased exertion, the "e-Sweat Bike Assist" [34], focuses on preventing the rider from reaching perspiration, by monitoring physiological signals, e.g. if the rider enters the sweat threshold, the engine support increases. Lastly, the "Digitsole" [12], an AI powered insole that monitors the rider's fatigue, balance, and cadence to coach the rider via audio to improve quality of movement.

These works suggest that designing systems that can "sense and act" on information during the exertion experience opens up an interesting design space. Where the system can focus on promoting co-operation, for example, by actuating the engine to support the rider "physically" to meet the required speed - and - by coaching the rider to support them "cognitively", facilitating the user and the system's skills to come together. However, these works mostly focused on the technical implementation perspective, hence there is little understanding about the associated user experiences and underlying design knowledge. From these works we learn about the potential of systems that can participate by acting on sensed information to facilitate co-operative exertion experiences. To deepen our understanding of this exciting new space, we formulate the following research question: "How do we design systems that can co-operate with the user to augment the exertion experience?". 


\section{ARI - AN AUGMENTED EBIKE}

Ari, a novel augmented eBike designed to explore usersystem co-operative exertion experiences, where the user and the system co-operate by using the information they each can sense, to regulate the speed and cross all traffic lights on green. Ari takes advantage of the "green wave" - a consecutive number of traffic lights running slightly off set, where a rider maintaining a reference speed set by the traffic authority, can benefit by getting all lights on green. Ari can accelerate the engine to assist the rider "physically" to meet the reference speed. It can also assist the rider "cognitively" by whispering via bone-conducting headphones to "slow down a little" [19] so the rider uses the breaks to regulate the speed. Ari gives riders a new form of augmented cycling experience promoting human-bike co-operation.

\section{SYSTEM DESIGN AND IMPLEMENTATION}

We have taken an incremental and exploratory approach for designing Ari, where the learnings gathered from each iteration informed the system design and implementation for the next iteration. As such the design inquiry for Ari was carried out in four iterations as explained below.

\section{Iteration 1: Design Considerations}

We were inspired by previous augmented cycling experiences that suggest that "design has to respect the distinctive nature of cycling as a mode of transport and needs to carefully interweave moments of interaction with it." [42], this notion guided our thinking. We conducted a couple of sessions with the cycling community around our research lab, which has riders from varied academic backgrounds, such as industrial design, computer science, sustainable transport, and HCI. We drew from their expertise to discuss, sketch and derive ideas to design our system as follows:

1. Interaction in motion is difficult $[24,30]-$ as the rider is cycling and focusing on the road, interacting with a screen device can be distracting and cognitively demanding. This informed our design to avoid screen interactions and let the experience afforded by cycling be the center of attention.

2. Communication and feedback occur regularly among users when co-operating, however, when systems do not provide regular feedback to users this can create friction [36] - this facilitated us to consider how the system could communicate with the rider, especially, as the rider needs to be aware of other riders and vehicles around them. For this reason, we used bone-conducting headphones, as this allows the user's ear to be uncovered to hear the environment while providing the system with direct access to the user. We limited the use of sound to two instances, a) a sound described as a power-boost is played when crossing a traffic light on green to reassure the user that the system is working as expected, b) the "slow down a little" sound aims to offer cognitive support, facilitating the system to pass on information to the user to slow down to regulate the speed.

3. Prior work suggests to fine-tune the assistance response to be gradual yet strong to offer an enjoyable experience [2] - this told us that we needed to experiment with the acceleration that Ari provided riders with to assist them meet the reference speed. We fine-tuned over multiple trials the acceleration, so the rider could experience the system increasing the acceleration gradually while allowing them to adjust, in case they needed to maneuver, or use the breaks.

4. For safety purposes, besides recruiting existing bike riders to minimise cycling risks, we decided that when the brakes are engaged, this leads to a cut-off of the eBike's engine.

These considerations informed the design of our prototype in parallel with implementation details that we describe next.
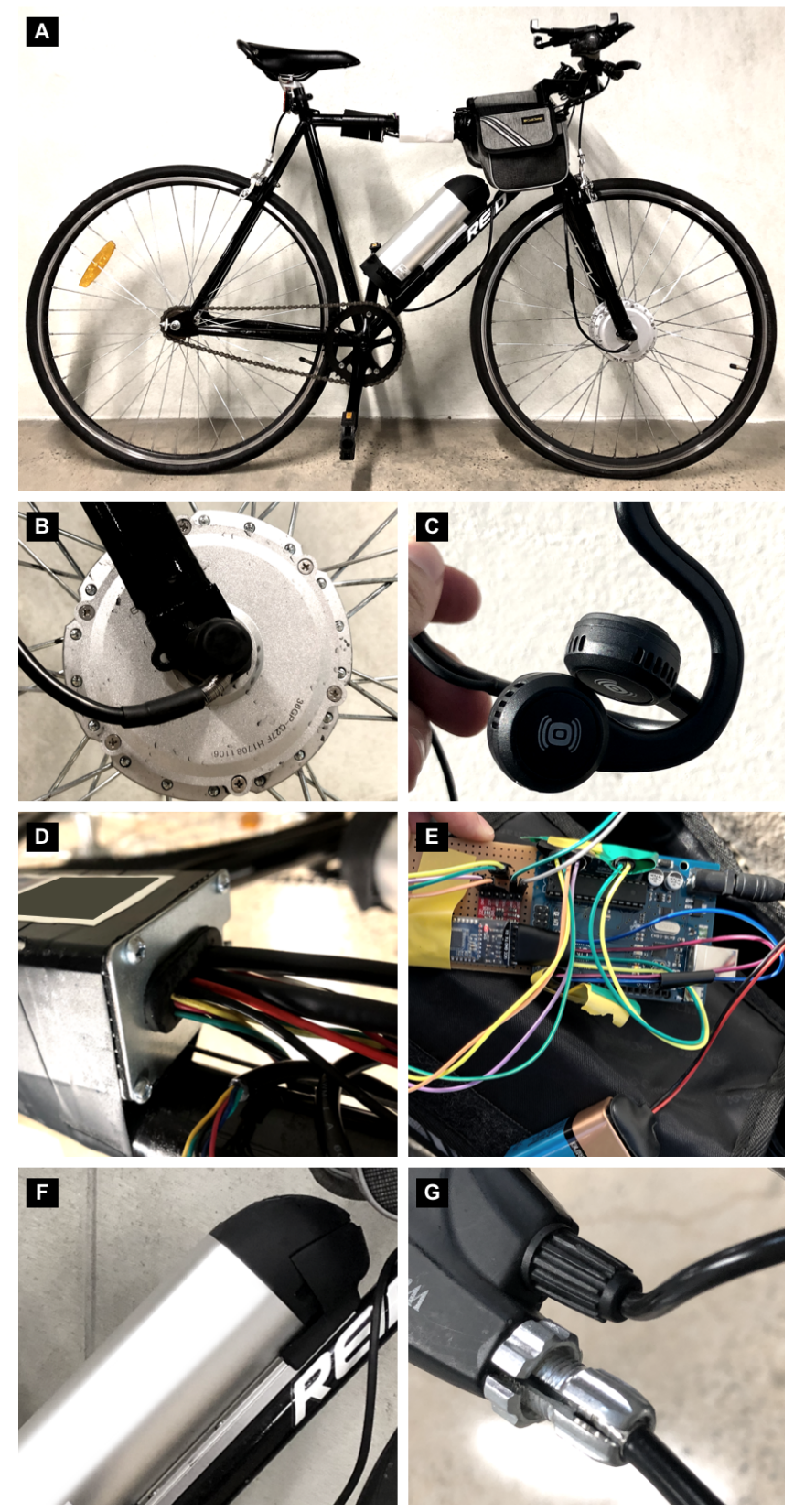

Figure 1. Ari an augmented eBike, A) Ari's body B) Brushless motor, C) Bone-conducting headphones, D) Motor controller, E) Arduino Uno, F) Battery, G) Brakes linked to motor controller. 


\section{System Implementation}

We converted a normal bike into an eBike by installing a brushless DC motor in the front wheel (Fig 1, B), along with the motor controller (Fig 1, D) and a 18V battery (Fig 1, F).

Our approach to coordinating the engine's acceleration and the slow down message was based on measuring the rider's speed using a smartphone's GPS, which we placed in the pannier. We built an iOS app to send the speed of the rider via Bluetooth to an Arduino Uno, to orchestrate one of the following: 1) if the rider speed is below the reference speed, the engine should be accelerated to assist the rider to meet the reference speed, 2) if the speed of the rider is greater than the reference speed, the slow down message is played to let the rider know to slow down, and 3) if the rider's speed is between $+-0.5 \mathrm{~km} / \mathrm{h}$ of the reference speed, nothing happens.

\section{Iteration 2: Studying Ari's Acceleration Response}

We selected a park with wide bike lanes and low road inclination. In our app, we simulated the traffic lights, and set a reference speed at $20 \mathrm{~km} / \mathrm{h}$. We found that a speed buffer of $+-0.5 \mathrm{~km} / \mathrm{h}$ avoids constantly triggering the acceleration and slow down message too often. After various sessions studying Ari's acceleration response we moved to the road.

Iteration 3: Using Open Traffic Data \& Moving to the Road We selected a $1 \mathrm{~km}$ long road with three traffic lights and low inclination. The road was selected based on available traffic data from the internet. Using a reference speed of $20 \mathrm{~km} / \mathrm{h}$ we had difficulty in crossing the lights on green due to the dynamic changes of the lights. In this stage we further finetuned the engine's acceleration to real traffic conditions.

\section{Iteration 4: Working with The Traffic Authority}

The traffic authority introduced us to SCATS, a dynamic intelligent transport system responsible for coordinating traffic light operations [29]. They suggested a new location for our study as part of the green wave trial in peak hour; according to their green wave modelling, $22 \mathrm{~km} / \mathrm{h}$ was the reference speed the rider needed to go to have the greatest chance of crossing all lights on green. We received CSV files containing the traffic light cycles for each light used in the green wave and their location. We visualized each light to identify four consecutive lights with the most consistent switching cycles to be the evaluation route (Fig 2). This allowed us to then set the reference speed, resulting in repeatable and consistent performance by our system.

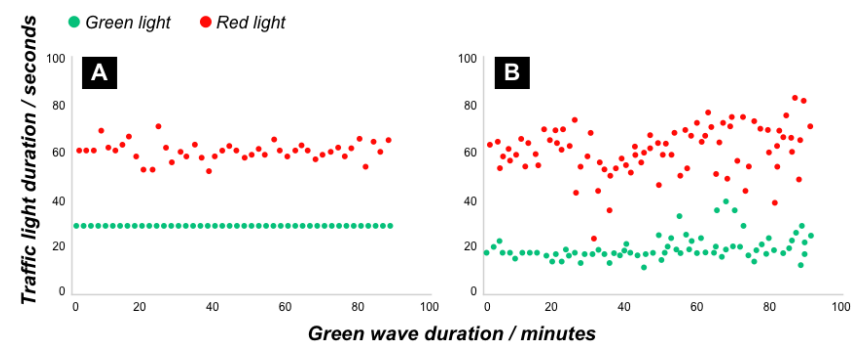

Figure 2. Visualization of a traffic light cycles, where A) shows a consistent green light duration of 30 seconds repeated over 90 minutes, B) shows less consistent cycles not suitable for our study.

\section{STUDY}

We built Ari to explore systems that can co-operate with the user to augment the exertion experience. We examine the human-bike interactions in co-operating to cross all traffic lights on green. Our aim is to consider what these interactions might tell us about systems that can co-operate with the user to augment the exertion experience and understand how to apply this design knowledge in theory and practice.

\section{Participants}

Ari was studied with 20 bike riders $(\mathrm{F}=6, \mathrm{M}=14)$, between the ages of $23-48$ years $(M=36, S D=7.7)$, recruited via advertisement and word of mouth. Our inclusion criteria were: a) participants had to know how to cycle so that cycling risks could be minimized, b) they cycle at least once a week, so that they had recent cycling experiences and could compare those with Ari. Ten of the participants had previous experience with eBikes, ranging between two weeks to four years of use.

\section{Setting}

The study lasted two months and it took place in mild weather, without rain, during weekdays' afternoon peak time between $4: 00 \mathrm{pm}$ and $6: 00 \mathrm{pm}$ to ensure predictability of the traffic lights. The road used for the study was straight, offered bike lanes, had four traffic lights, and was $1.2 \mathrm{~km}$ long with $24 \mathrm{~m}$ inclination. In average, it took participants about 7 minutes to cycle from start to end.

\section{Procedure}

Participants were invited to the location, using a map on a smartphone we showed participants the four traffic light intersections they should cycle through.

We used two eBikes, Ari and a regular pedal-assist eBike. The pedal assist-eBike or pedelec is the "default" eBike available in shops, where the user accesses the engine's assistance by pedaling. In other words, the pedal assist-eBike only accelerates the engine upon the rider pedalling hard and not by sensing and acting on information. Using these two distinct interactive systems allowed riders to contrast Ari's "sensing and acting" against the pedal assist-eBike that required user input to offer acceleration assistance. We believe that a benefit of having two participants cycle together is that we were able to observe initial social aspects of cycling and the effect of our prototype on other riders.

The two participants who did not know each other and were not instructed to cycle together, started cycling the $1.2 \mathrm{~km}$ road at the same time, one using Ari and the other the pedal assist-eBike. Participants started from the low inclination point and cycled to the end which had the highest inclination of $24 \mathrm{~m}$. Once participants arrived at the end, they cycled back to the starting point, this was not part of the study and Ari was not programmed to respond. Upon returning to the starting point, participants were interviewed before we asked them to switch bikes and cycle again. In total, all participants cycled six times on the selected road, experiencing each eBike three times, resulting in an approximately 45 minutes long cycling experience. 


\section{Data Collection}

We interviewed the two participants together every time after completing the course and before switching eBikes. For the interviews, we used the explicitation approach $[37,48]$. This retrospective interview technique seeks first-person accounts and is often employed after an experience has happened. One of the benefits is that interviewers ask questions in relation to specific moments of the experience in a chronological order of events to learn about how the experience unfolded from the participant's perspective. This approach allowed us to capture in-situ experiences including tactile details which often rapidly decay in the user's memory [20, 37]. As participants were interviewed every time in-between switching eBikes, it appeared to facilitate them to be more observant when re-trying Ari based on aspects that arose through interviewing, their observations were then reported on the next switch of eBikes. Every participant pair was interviewed for approximately 50 minutes.

\section{Data Analysis}

We used an inductive thematic analysis [6] approach to the data. Interviews were transcribed and imported into Nvivo for analysis. Two researchers independently coded and described the data. The researchers compared their codes and descriptions and filtered them by merging clusters and discussing the data over a series of meetings. This resulted in fewer codes, which led to themes. The themes and our experience in designing the system resulted in tactics targeted at designers who aim to design user-system cooperative experiences to augment the exertion experience.

\section{RESULTS}

We present the results in the form of themes with a total of 216 units coded. The results follow a chronological order of events to symbolize the user's building blocks to reach a cooperative user experience.

\section{Theme 1: Meeting the System}

This theme describes 34 units and it has two categories: Participants' Curiosity About How the System Works (7 Units), and Expectations of Ari (27).

Participants' Curiosity About How the System Works Participants explored how the system worked by asking: "Is this bike actually integrated with the traffic lights or is it a timetable hard coded thing?". More analytically-minded participants focused on understanding how the system worked to predict the acceleration. Participants also discussed within their pairing: "It's not fully hardcoded because it's sensing your speed in relation to the reference speed. So I would say some aspects are 'real' sensing while the traffic light 'speed' is fixed.".

Other participants preferred to try things on the eBike: "I pedaled less to see if the system would feel more predictable and it did. I could understand how it works a little better", "I pedaled fast to try and get it <Ari> to say slow down. I understood how much faster I have to go for the sound to come up, or how slow I can go before the system picks up, to see how predictable it is".
Once participants asked questions and tried the system, few did not like not knowing when the system was going to accelerate (6 units): "I felt that it was speeding up and slowing down when I didn't want it to... the light was green and it wasn't accelerating, I didn't understand why". In this case the system did not slow down the speed, but rather stopped accelerating the engine when it was not needed. Participants reported that initially cycling with Ari was clumsy: "I didn't do much just to see what it would do and follow, it reminded me of learning to dance". Over time, participants became more familiar: "It takes a ride at least to experience this type of control, you can do everything but now acceleration is not controlled by you".

Participants utilized a mixture of questions, practical exercises and discussion to explore how the system worked and how to co-operate with it.

\section{Expectations of Ari}

Participants' expectations ranged from seeing Ari as a prototype: “...this was a prototype and I didn't want to ruin it, I was cautious" to seeing Ari as an Artificially Intelligent Bike "it's just a really cool and crazy idea to think that you're on an eBike which knows and adjust to its environments, like an AI eBike... It's a little bit scary but also really exciting". Participants referred to Ari during the interviews in different ways: "AI bike", "smart bike", "cyber-horse.

Participants wished that Ari could be aware of other cyclists (5 units), "We caught up with few cyclists when the bike was starting to accelerate, even after braking a bit the bike would still try to accelerate. The bike should be aware of other cyclists because you cannot overtake them sometimes". This relates to participants trying to understand how to co-operate with Ari in new situations. In other instances, participants reported that Ari would not allow them to reach high speeds despite the fact that they were pedaling hard (4 units): "No matter how slow or fast you pedal, the bike knows how fast it wants to go". Ari was not programmed to use the brakes.

After two rounds, participants discussed possible use cases for Ari: "You want to get from A to B, you give up a bit of the control and trust the bike, and the bike just goes like, 'Yes, I'm going to get you there in the most efficient way possible.' ... until there's a situation in which you need a human brain to assist the bike". This relates to participants reporting that they had to be aware of the environment to intervene when there was something that the eBike could not be aware of.

Participants also described what Ari is not good for, "When I commute this is perfect, a healthy way to get to work and, no one likes stopping at red lights. Obviously, that's not what you want when you're just riding a bike for leisure on the weekend because you want to enjoy going fast when you want and slowing down when you want..."

This reminds us about the balance that designers need to consider when designing interactive system, as the borders between the user and system actions can cause friction, but also open opportunities for co-operation. Participants' 
expectations of the system shifted through their interactions: "It takes a shift in your expectation of the bike but once you've made that little shift then it's actually peaceful'.

Theme 2: Learning to Co-operate with the System

This theme describes 137 units and it has four categories: When the system acted (35), Users' experience of sound (28), Building Trust with the system (28), and Co-operating with the system (46).

\section{When the System Acted}

Participants reflected on Ari's actions: "The bike started to accelerate towards a red light. If I had been cycling on my own, I wouldn't have started accelerating at that point because I didn't know that the light was going to change”.

Due to Ari's knowledge of the reference speed, at times, Ari did not need to accelerate as the reference speed was met, "I was hoping it <Ari > would accelerate but it didn't. I was pedaling hard to get to the green light and I did, but it wasn't accelerating". Participants shared specific details about the moment when Ari acted by accelerating the engine, "It felt a little bit unpredictable. I didn't engage it myself, so I wasn't aware when it would stop. It was about two seconds long over 15-20 meters?".

Participants appeared to expect crossing the traffic lights while Ari was accelerating to get the extra boost, rather than only using their input (12 units). Crossing each traffic light appears to be seen as a finishing line where a sense of victory is elicited from: "Every light is like a separate challenge, when you cross it you move up to the next challenge", "When you cross the traffic light on green it's like a victory, and you become addicted to getting more green lights <laughs $>$ ".

Participants reported the idea that Ari was taking them for a ride (7 units): "...It definitely felt like the bike was taking me as opposed to me riding the bike, it has some mystery as I don't know when it will stop accelerating, but I don't mind it since it's perfectly in sync with the lights". Comments like these highlight the moments when Ari participated, facilitating the rider to perceive the "presence" of Ari and its effect on the situation, "I see like a co-existence between me and the bike. I can trust it to accelerate for me, but...in the first trial when the bike accelerated for me and I chose not to use the breaks, even if it means to put myself in a dangerous situation because I want to get the green light".

\section{Users' Experience of Sound}

We mentioned to participants that sounds were going to be played via the bone-conducting headphones during cycling, however, we did not specify what the sound or message were with the aim of having participants explain to us what the sound did for them during the experience. The traffic lights crossing sound was received with mixed opinions, while the message to "slow down a little" was positively received.

Participants identified the traffic light crossing sound with the system working properly: "The bike knows where I am, that's good", "It's a good indication that it's working, the system is doing its thing". Participants also associated the sound with a celebration "It might have been like, 'congrats, you made it successfully through a green light",. Others, however, were confused about the meaning of the sound when crossing the lights: "I didn't get it and it didn't come a time where I felt that I needed to accelerate", "I don't know exactly what it was trying to tell me". This relates to the moment where users tried to interpret what the sound meant, and how this affected their experience.

In other cases the sound facilitated riders to experience a connection and sense of co-operation with the eBike, "It $<$ the sound effect $>$ was just a novel sensation of having a different sense <hearing $>$ of connection with the bike that you wouldn't normally use", "The sound gives the perception that you are collaborating with the bike when you choose to slow down after hearing the sound".

Participants that experienced the traffic light crossing sound as a power boost sound expected Ari to be accelerating at the same time. However, if the reference speed was met, Ari did not need to accelerate: "I got the power-boost sound when I made it through the green lights, I think it might have been a little out of sync with the bike's boost, you'd expect the bike to power when it plays the sound". In contrast, few participants interpreted the sound as Ari telling them to accelerate by pedaling harder (3 units): "I thought that the sound was telling me to accelerate, and since I don't control the acceleration, I just pedaled harder".

Participants argued for the use of the traffic lights crossing sound: "There is already joy in crossing the green lights. If you remove distractions, you may improve the act of cycling". Participants proposed alternatives: "The eBike could alert you before accelerating with a few bleeps". This sound alert may aid riders with reducing the unpredictability of the eBike accelerating and could improve co-operation.

\section{Building Trust with the System}

Trust in the system was gained through repetitive actions, such as delivering on the promise of co-operating with the rider to cross the traffic lights while green. Crossing many lights while green increased participants' trust in the system, "I was skeptical of the bike, after crossing two lights green I thought maybe this is actually reliable", "It got me through successfully the first time, so when I did the second time, I trusted it a bit more that it would do so again".

Sound contributed to building trust, as this reassured users that the system was working with them: "...feedback provides confirmation that that's what it's meant to do. It was very clear this time that the power-up sound happened right as we passed through green lights", "You almost feel like you should do what the sounds are telling you, because you know that it's going to benefit you".

Trust appeared to be weakened when the system does not meet expectations or appears to change the way in which it participates. This tells us that a degree of predictability with the system can aid with trusting the system: "After I released 
the breaks the bike decided to accelerate. Maybe the bike should learn that braking multiple times means 'Don't accelerate",". Ari did not have intelligence to learn about the use of the brakes and what it could mean from a contextual perspective. During times like these, it appears as if Ari is challenging the authority of the rider and proceeds to work individually rather than with the rider.

There may have been a momentary negotiation of authority, when the eBike was accelerating but the rider could see obstacles ahead: "I felt like I wanted to take the risk of putting myself in between you <the other rider $>$ and the car passing by because I thought 'Oh the bike was picking up to get the green lights' so, therefore I shouldn't slow it down even if that could put me in a risky situation". Moments like this highlighted that the rider was able to identify a context that Ari did not know about - for example, understanding the road condition, such as other cyclists, obstacles ahead and proximity of vehicles. Through practice with situations like this, the user improves his/her ability to co-operate with the system and this appears to yield more trust in the system.

\section{Co-operating with the System}

Participants explained that they experienced co-operating with the system: "I recently started eBike riding, the traffic light bike took away the uncertainty that somebody would have about going too fast or too slow", "It felt like a guided bike riding, like the bike was my teacher almost". Other participants described the exact moment when they thought they had co-operated with the eBike: "The sweet spot was when I was like 10, 15 meters from the light and the bike kicked in, I did not have to pedal as much, we went straight through", "I let the eBike go and If there was car in front of us or some unexpected situation because the smart bike won't see and I can. I could take the tool back using the brakes". Participants became more comfortable with letting the system accelerate and with actioning the slow down message. This adjustment in cycling facilitated participants to become more efficient in getting the traffic lights on green by co-operating with the eBike to regulate the speed.

Furthermore, understanding the eBike's actions is important for co-existence, because as the user accumulates experience and learns to adjust to the system, the co-operation appears to become more enjoyable: "I felt there was co-existence because both parties did their part, it was smooth, but if the eBike was impatient, like I feel impatience, or felt the need for speed like I do sometimes. Then the bike could ignore its own best intentions and put me in dangerous situations".

More details emerged when participants were asked to describe what it was like to cycle with Ari, "I think the traffic light bike might be co-operative. I'd say the pedal assist augments your cycling, whereas the traffic light bike can do things that you can't and you can do things that it can't. You're sort of balancing all those skills, it's like your buddy, it knows where the traffic lights are at, but it doesn't have eyes. You have eyes, so you're like, 'I'll take care of you. You take care of me', so, 'You do the traffic light thing. I'll make sure we don't hit anything"," "The pedal-assist it's kind of dumb, you pedal and it assists you and that's it. The other bike knows how to get green lights, however, you relinquish some control to the bike because it can accelerate, but you still have control of braking, left, right, stop, start".

Comments like these suggest that participants grasped the idea that adjusting to cycling with Ari allows them to integrate their skills and facilitate co-operation.

\section{Theme 3: Social Aspects of Cycling.}

This theme describes 9 units.

\section{Riders Adjusted their Cycling Efforts to Benefit from Ari}

Participant's described when they changed their cycling to be closer to the rider on Ari: "I could have gone faster, but I wanted to avoid breaking at the lights and have to gain momentum again, so I just followed him <the rider on Ari> to see if I could also get the lights". Even though participants did not know each other, in some cases, they followed the rider on Ari, due to the augmented capability to co-operate with the rider to get green lights: "I trusted wholeheartedly in Robert's < the other rider > acceleration and deceleration and followed him as close as I could. We got all the green lights together". This shows that participants adjusted their cycling efforts to benefit from cycling along with Ari.

Riders can be Envious but also Proud of Co-operative Cycling Participants contrasted their experiences between the two bikes "He shot three or four meters in front of me before the second traffic light, I pedaled quickly to catch up with him because I thought that meant the light was changing. I felt a little annoyed because I did not know about it and he did", "When I cycled with the traffic light bike, it was like if the eBike was my assistant and I could cycle better”.

Giving Away Control Leads to More Careful Social Cycling Participants planned how to cycle: "We were cycling next to each other, he said, 'Hey, please be careful, sometimes this bike is accelerating, it's better if you go first and I go behind"'. Participants created strategies to cycle more carefully, this may have been due to Ari's rider learning to control the acceleration provided by Ari.

\section{Theme 4: Reminiscing Moments (9 units)}

We asked participants if cycling with Ari reminded them of other experiences, to which they said: "When someone pushes you on a swing, you don't know if they will keep pushing". This relates to participants not knowing when Ari was going to accelerate. Others made comparisons to animals (6 units), "A horse, you ride it like a bike and it can sense things that humans can't. Similarly bats or dolphins with echolocation”, “... is almost like a cyber-horse, you let the bike be a horse and it goes by itself", "horse riding, because the acceleration kicks in without you requesting it", "Like a dog can smell things that you can't, but it can alert you". This relates to the extra sensing capabilities that Ari has and how the user can gain information to regulate the speed. We explore the similarities between human-animal and human-system co-operation under design tactics. 


\section{Theme 5: Participants' Suggestions (27 units)}

Participants made suggestions about the moments when Ari is about to accelerate, "There was voice guidance to tell me to slow down but I did not know when the bike was going to accelerate. I'd expect voice guidance to announce the acceleration too". Voice announcement may aid the user to learn faster to adjust to co-operate with Ari and it could contribute to lower uncertainty. Furthermore, voice or sounds, or engaging other senses to deliver information, could facilitate opportunities to improve co-operation.

Other suggestions focused on gaining knowledge about the traffic lights through Ari so that the rider could predict what is about to happen: "If it gave you a sound warning when the light is going to change few seconds before, 'Hoot. Hoot. Hoot."," "A countdown to green because then maybe I could speed off on my own and I wouldn't need the assistance”.

Participants suggested that the eBike could provide a data log showing how the rider and the eBike regulated the speed (6 units), "With any kind of intelligent system it takes time for humans to build up trust. If, after a trip it showed the data of how it did it, you could look and be like, 'I sped up here and then maybe just made the traffic light', this may be reassuring”. Others wished for additional information during cycling, "Maybe additional traffic info about upcoming roads in your path, via the headphones".

Suggestions in relation to conversing with Ari were discussed (3 units), "If it could tell you in some way that is about to do something, or if you could tell the eBike about other riders and not to accelerate". This suggestion may be useful to further co-operating with the system.

\section{DESIGN TACTICS}

We present six design tactics that emerged from the study results, our experience in building the system, and discussion and refinements among the authors and collaborators.

Tactic 1: Contextual Cues to Facilitate Skill Integration This strategy builds from: Expectations of Ari (T1), Users' Experience of Sound, and Co-operating with the System (T2), and Social Aspects of Cycling (T3).

Skill integration is the premise for co-operation, according to Doran et al. [14] co-operation happens when the actions of each user/system satisfy either or both of the following:

- The user and the system have a goal in common.

- The user and the system perform actions to enable or achieve not only their own goals, but also the goals of others.

To achieve the common goal the user and the system pass on information to each other based on the sensing capabilities they have. In the case of Ari, the user and the system could sense and act on different information during cycling, which allowed them together to regulate the speed to cross all traffic lights on green. Contextual cues such as "slow down a little" facilitated passing on information from the system to the user, who then executed this instruction by slowing down, resulting in skill integration.
To facilitate skill integration, we suggest:

- The user should understand the benefit of co-operating, this will assist them in considering and valuing co-operating.

- The system uses brief contextual cues that the user can easily action, this will reduce operational complexity for adhoc execution.

- The system adapts its contribution according to the user's efforts, this allows the user to grasp the dynamics of the cooperation and adjust their own contribution.

- There is a bilateral relation when it comes to shaping each other (the user and the system) through interaction to improve co-operation - rather than, only a unilateral relation where either the user or the system adjusts to the other. This will allow the user and the system to co-operate more effectively through practice.

Tactic 2: Contextual Meaning to Craft System Response This strategy builds from: Expectations of Ari (T1), Users' Experience of Sound, When the System Acted (T2), and Social Aspects of Cycling (T3).

Users often perceived each traffic light as a finishing line and expected the traffic light's crossing sound to be accompanied by Ari's acceleration while crossing. Ari was not designed to always accelerate while crossing the traffic lights as its acceleration was determined by meeting the reference speed.

Designers could enquire about the users' contextual meaning of the environment, such as perceiving the traffic lights as finishing lines, with the aim of crafting the system's response. This can facilitate designers with design ideas to craft the experience around contextual meaning, resulting in experiences that fulfill or challenge the user's expectations.

Another example relates to the system not being aware of other cyclists and the rider pressing the brakes multiple times to stop the acceleration. Capturing such occurrences can serve designers with crafting the system to respond according to the situation, and it may also inform opportunities to customize the system to a particular user's interaction. This customization can build on the idea that through interaction the user and the system shape each other to attain better co-operation [50].

Tactic 3: Drawing From Human-Animal Co-operation to Inform Human-System Co-operation

This strategy builds from: Building Trust with the System (T2), Reminiscing Moments (T4).

Participants drew comparisons between animals and Ari, due to the complementation of skills: the rider was responsible for pedalling, navigating and manoeuvring, while Ari was responsible for monitoring the speed, accelerating the engine, and informing the rider if going too fast. Humans and Animals have co-operated previously (e.g. guide dogs [35], dog - shepherd [26], and rider - horse [22]), in this tactic, designers can consider the similarities between humananimal and human-system co-operation for future designs: 


\begin{tabular}{|c|c|c|}
\hline User Actions & Co-op Animal & Co-op System \\
\hline Feeding & $\mathrm{x}$ & Via the battery \\
\hline Cleaning & $\mathrm{x}$ & General Maintenance \\
\hline $\begin{array}{l}\text { Keep up with } \\
\text { vaccinations }\end{array}$ & $\mathrm{x}$ & $\begin{array}{l}\text { Maintain software } \\
\text { updates for security / } \\
\text { functionality }\end{array}$ \\
\hline $\begin{array}{l}\text { Analyze poo to } \\
\text { learn about its } \\
\text { well-being / } \\
\text { performance }\end{array}$ & $\mathrm{x}$ & $\begin{array}{l}\text { Analyze the system's } \\
\text { activity log to learn } \\
\text { about its performance }\end{array}$ \\
\hline $\begin{array}{l}\text { Adjustment over } \\
\text { repeated use for } \\
\text { better co-op }\end{array}$ & $\begin{array}{l}\text { It learns through } \\
\text { practice }\end{array}$ & $\begin{array}{l}\text { It can be designed to } \\
\text { adjust to the user's } \\
\text { repeated interactions }\end{array}$ \\
\hline $\begin{array}{l}\text { I seek to trust the } \\
\text { animal to build } \\
\text { co-op }\end{array}$ & $\begin{array}{l}\text { It develops a } \\
\text { bond with the } \\
\text { owner }\end{array}$ & $\begin{array}{l}\text { It can be designed to } \\
\text { gain the user's trust } \\
\text { (Tactic } 4 \text { ) }\end{array}$ \\
\hline $\begin{array}{l}\text { Rewards / } \\
\text { Punishes for } \\
\text { training }\end{array}$ & $\begin{array}{l}\text { Its receptive and } \\
\text { learns from }\end{array}$ & $\begin{array}{l}\text { It can be designed } \\
\text { with reward / } \\
\text { punishment feedback } \\
\text { loop }\end{array}$ \\
\hline $\begin{array}{l}\text { It has emotions } \\
\text { (e.g. impatience) } \\
\text { and personality }\end{array}$ & $\begin{array}{l}\text { It has emotions } \\
\text { and personality }\end{array}$ & $\begin{array}{l}\text { It can be designed to } \\
\text { showcase emotions } \\
\text { and personality }\end{array}$ \\
\hline $\begin{array}{l}\text { There is } \\
\text { hierarchy, the } \\
\text { leader can gain } \\
\text { control through } \\
\text { commands }\end{array}$ & $\begin{array}{l}\text { It often } \\
\text { responds to the } \\
\text { leader via } \\
\text { commands }\end{array}$ & $\begin{array}{l}\text { It can be designed to } \\
\text { show different levels } \\
\text { of obedience } \\
\text { (Tactic } 6 \text { ) }\end{array}$ \\
\hline
\end{tabular}

Table 1. Similarities in Human-Animal \& Human-System Co-op

Animal co-operation literature has focused on questions such as: "When to co-operate?", "With whom to co-operate?", "What to do in co-operative interactions?", and, "How much to contribute to co-operation?" [31]. We believe designers of co-operative systems can also ask these questions to form a foundational understanding in their designs.

\section{Tactic 4: Making Co-operative Systems More Trustworthy \\ This strategy builds from: Expectations of Ari (T1), Users' Experience of Sound, Building Trust with the System, and Co-operating with the System (T2).}

Trust is a larger challenge when systems can co-operate with the user during the experience. Due to the fact that trust facilitates acceptance and can also define how users interact with technology [45].

By design, co-operative systems could "communicate" with the user to gain their trust - communication enhances cooperation [50], because it links meaning and action [13], facilitating user-system co-operation.

Ari used two sounds to communicate. The traffic light's crossing sound was intended to reassure the user that the system was working, however, this sound was abstract and led to multiple interpretations. Over time it became a burden as the user knew the system was working. We suggest fading out reassurance communications, if the user can perceive the system is performing as expected. As co-operation improves, designers should aim for uninterrupted co-operation.

The second sound, "slow down a little", was derived from the system sensing the speed to determine if the user needed to slow down to meet the reference speed. Once the system identified that the user was going faster than the reference speed, it generated the message to facilitate the link between meaning and the user then actioning this, to slow down, facilitating co-operation.

For complex operations we suggest using brief voice messages as meaningful actionable instructions during the experience. Less complex actions could focus on using abstract sounds or even haptics after the user has learned the meaning of such communications.

Text as a form of communication could be used in a post activity $\log$ to facilitate reflecting on how the co-operation unfolded. This can provide the user with insights into the system's performance and promote trust in future operations.

Conversational capabilities were suggested for Ari, here designers can draw from the large body of research in conversational agents and personality (e.g. [8, 32, 44]). For this approach we suggest making conversations brief and instructional during the activity to pass on actionable insights that benefit the experience.

\section{Tactic 5: Making Co-operative Systems Inclusive}

This strategy builds from: Expectations of Ari (T1), and Participants Suggestions (T5).

By design, co-operative systems can be more inclusive than systems that depend on user input. By reason that cooperative systems can "sense and act" to compensate the user's efforts in relation to joint operations.

As an example, consider the co-operation between service animals and the visually impaired: as the user's vision deteriorates over time, the service animal will take on more responsibilities, due to the fact that it can "sense and act" to adjust to the co-operation. Similarly, co-operative systems can adjust their contribution according to the user's abilities improving or deteriorating over time.

As proposed in Tactic 4, making co-operative systems more trustworthy, can result in making the experience more inclusive. The system can be informative and complementary to the user's awareness [1] and it can also adjust its language and choose a suitable user sense to engage with (e.g. instead of voice messages for users without hearing, explore haptics as an alternative [23]). Co-operative systems can facilitate less-able users to participate in social situations not previously possible. Due to the system complementing the user's physical and cognitive abilities in relation to the activity. One such example is group cycling; the system could complement the rider's physical efforts to keep up with the cycling group. 
Tactic 6: Adjusting the User's Perception of Control Over the Co-operative System

This strategy builds from: Participant's Curiosity About How the System Works, Expectations of Ari (T1), When the System Acted, and Users' Experience of Sound (T2).

Users' perceived level of control over Ari varied for multiple reasons, such as trusting in the system, how comfortable they felt cycling, and how much experience they had. This tactic shows how the perceived level of control over the cooperative system can result in different user experiences that designers can consider when crafting co-operative systems.

User's Perception of Control Over the Co-operative System

\begin{tabular}{|c|c|c|}
\hline Low & Medium & High \\
\hline \multicolumn{3}{|c|}{ Situational Examples from Our Study } \\
\hline $\begin{array}{l}\text { The user is } \\
\text { skeptical of the } \\
\text { system. Their } \\
\text { trust in the system } \\
\text { is diminished } \\
\text { through } \\
\text { experiences that } \\
\text { did not meet their } \\
\text { expectations }\end{array}$ & $\begin{array}{l}\text { The user regularly } \\
\text { tests the system to } \\
\text { explore its } \\
\text { response and } \\
\text { predictability - } \\
\text { they are finding a } \\
\text { middle ground to } \\
\text { improve co- } \\
\text { operation }\end{array}$ & $\begin{array}{l}\text { The user adjusts to } \\
\text { co-operating with } \\
\text { the system: they } \\
\text { understand the tasks } \\
\text { they are responsible } \\
\text { for. They let the } \\
\text { system go as they } \\
\text { know that they can } \\
\text { regain control }\end{array}$ \\
\hline \multicolumn{3}{|c|}{ Resulting User Experience Terms and Key Quotes } \\
\hline $\begin{array}{l}\text { Conflicting UX } \\
\text { The user has } \\
\text { difficulty letting } \\
\text { go of control, they } \\
\text { do not enjoy the } \\
\text { system's actions } \\
\text { and try to } \\
\text { overwrite them. } \\
\text { "I did not } \\
\text { understand why it } \\
\text { was slowing } \\
\text { down, it was } \\
\text { unpredictable" }\end{array}$ & $\begin{array}{l}\text { Fiddly UX } \\
\text { The user fiddles } \\
\text { with the system } \\
\text { seeking an } \\
\text { explanation for } \\
\text { the systems } \\
\text { actions - back and } \\
\text { forth in a clumsy } \\
\text { experience. } \\
\text { "I pedaled less to } \\
\text { understand it, it, } \\
\text { reminded me of } \\
\text { learning to } \\
\text { dance" }\end{array}$ & $\begin{array}{l}\text { Co-operative UX } \\
\text { The user perceives } \\
\text { they are in control } \\
\text { and leverage the } \\
\text { system for their } \\
\text { benefit, they } \\
\text { understand that co- } \\
\text { operating increases } \\
\text { their skills. } \\
\text { "I cycle better, } \\
\text { more effectively, } \\
\text { you're sort of } \\
\text { balancing all those } \\
\text { skills, It's like your } \\
\text { buddy" }\end{array}$ \\
\hline
\end{tabular}

Table 2. User's Perception of Control Over the Co-operative System and the Resulting User Experience

We see that the user's perception of control over the cooperative system is transitional - progressing from low to high. This tactic aids designers by highlighting "things to look out for" using the Situational Examples and Resulting User Experiences. Designers can then leverage the presented tactics to iterate their design to assist users' reach the cooperative stage.

\section{FUTURE WORK}

We have begun to understand that systems that can "sense and act" on information offer co-operative opportunities to augment the exertion experience. As a result, we highlight future work in this emerging area as follows:

Using themes 2, 3 and tactics 1 and 5 to investigate cooperative experiences among multiple users and systems. e.g. group eBike cycling, exoskeletons group performance in super human sports, military operations, and dance.

Using themes 1, 5 and tactics 4 and 6 to investigate cooperative systems as "coaches", supporting the user develop new skills. e.g. a coaching eWheelchair that complements the user's efforts while teaching operational maneuvers.

Using theme 4 and tactics 2 and 3, to investigate bilateral user-system adjustment. e.g. by considering the environment in which joint operations occur and drawing from humananimal co-operation learning feedback loops towards creating personalized user-system co-operation.

Considering safety in co-operative exertion systems via extra sensing capabilities, such as, proximity to moving objects via front and rear cameras to inform the system's acceleration may be a logical progression to further our system.

Investigations into user-system co-operation over longer time spans, is something that we did not study and could yield interesting insights to inform future designs.

\section{CONCLUSION}

We designed Ari, 'the eBike', to study human-system partnership, in an exertion experience context, in which the user and the system work together using their sensing capabilities to regulate the speed and cross traffic lights on green. Ari assists the rider to meet a reference speed of $22 \mathrm{Km} / \mathrm{h}$ to catch the traffic lights on the greenwave. It does so by gradually accelerating the engine when the rider is below $22 \mathrm{~km} / \mathrm{h}$ to assist them "physically" - if the rider is going faster than $22 \mathrm{~km} / \mathrm{h}$, Ari whispers via bone-conducting headphones to "slow down a little", to support the rider "cognitively", so that he/she can use the breaks to regulate the speed.

With this work we contribute to the intersection between human-computer integration, where the user and computer co-operate in partnership [16], and exertion support, where the user invests physical effort [18], an emerging area in HCI. Through an explicitation approach $[37,48]$ to the interviews with 20 bike riders and using thematic analysis [6], we synthesized five themes and six design tactics to further the design of interactive systems at the intersection of human-computer integration in an exertion context, thereby facilitating user-system co-operation to augment the exertion experience.

\section{ACKNOWLEDGMENTS}

We thank the reviewers for their insightful feedback, RMIT University's David Taylor, VicRoads Anna Evangelista and Syrina Pi for their greenwave and traffic guidance, IBM's Julian de Hoog for his support, and Melbourne University's Eric Zhang, Hank Shuohengxie and Diqi Wang for their electrical engineering efforts. 


\section{REFERENCES}

[1] Julio Abascal and Colette Nicolle. Moving Towards Inclusive Design Guidelines for Socially and Ethically Aware HCI. Interacting with computers 17, 5 (2005), 484-505 https://doi.org/10.1016/j.intcom.2005.03.002

[2] Josh Andres, Julian de Hoog and Florian Mueller. "I Had Super-Powers When Ebike Riding" Towards Understanding the Design of Integrated Exertion. Proceedings of the 2018 Annual Symposium on Computer-Human Interaction in Play (2018). https://doi.org/10.1145/3242671.3242688

[3] Josh Andres, Julian de Hoog, Jürg von Känel, Julian Berk, Bach Le, Xizi Wang, Marcus Brazil and Florian Mueller. 2016. Exploring Human: Ebike Interaction to Support Rider Autonomy. In Proceedings of the 2016 Annual Symposium on Computer-Human Interaction in Play Companion Extended Abstracts. ACM, 85-92. https://dx.doi.org/10.1145/2968120.2987719

[4] Giancarlo Bacchieri, Aluísio JD Barros, Janaina V Dos Santos and Denise P Gigante. Cycling to Work in Brazil: Users Profile, Risk Behaviors, and Traffic Accident Occurrence. Accident Analysis \& Prevention 42, 4 (2010), 1025-1030.

https://doi.org/10.1016/j.aap.2009.12.009

[5] Cobi Bike. 2018. Cobi Bike. https://cobi.bike/product.

[6] Virginia Braun and Victoria Clarke. Using Thematic Analysis in Psychology. Qualitative research in psychology 3, 2 (2006), 77-101.

http://dx.doi.org/10.1191/1478088706qp063oa

[7] Tadej Brezina and Bernd Hildebrandt. 2013. Where Do Cyclists Run Red Lights? An Investigation into Infrastructural Circumstances. In Proceedings of ICTTE-International Conference on Traffic and Transport Engineering, COKORILO, O.(Ed.) Beograd, Srbija: City Net Scientific Research Center Ltd., Beograd. 109-114.

[8] Andrew J Cowell and Kay M Stanney. 2003. Embodiment and Interaction Guidelines for Designing Credible, Trustworthy Embodied Conversational Agents. In Proceedings of International Workshop on Intelligent Virtual Agents. Springer, 301-309. https://doi.org/10.1007/978-3-540-39396-2_50

[9] CycleLabs. 2015. Smarthalo. https://www.kickstarter.com/projects/1106460188/sm arthalo-turn-your-bike-into-a-smart-bike/description.

[10] Alexandru Dancu, Velko Vechev, Adviye Ay, Simon Nilson, Oscar Nygren, Simon Eliasson, Jean-Elie Barjonet, Joe Marshall and Morten Fjeld. 2015. Gesture Bike: Examining Projection Surfaces and Turn Signal Systems for Urban Cycling. In Proceedings of the 2015 International Conference on Interactive Tabletops \& Surfaces. ACM, 2817748, 151-159. http://dx.doi.org/10.1145/2817721.2817748

[11] Daniel H De La Iglesia, Juan F De Paz, Gabriel Villarrubia González, Alberto L Barriuso, Javier Bajo and Juan M Corchado. Increasing the Intensity over
Time of an Electric-Assist Bike Based on the User and Route: The Bike Becomes the Gym. Sensors 18, 1 (2018), 220. 10.3390/s18010220

[12] Digitsole. 2018. Digitsole AI Powered Insoles for Cyling. https://www.digitsole.com/connected-insolescycling-run-profiler-cycling/.

[13] Anne Donnellon, Barbara Gray and Michel G Bougon. Communication, Meaning, and Organized Action. Administrative Science Quarterly (1986), 43-55. http://dx.doi.org/10.2307/2392765

[14] Jim E Doran, SRJN Franklin, Nicholas R Jennings and Timothy J Norman. On Cooperation in Multi-Agent Systems. The Knowledge Engineering Review 12, 3 (1997), 309-314. 10.1017/S0269888997003111

[15] Umer Farooq and Jonathan Grudin. Human-Computer Integration. Interactions 23, 6 (2016), 26-32. $10.1145 / 3001896$

[16] Umer Farooq and Jonathan T. Grudin. 2017. Paradigm Shift from Human Computer Interaction to Integration. In Proceedings of the $2017 \mathrm{CHI}$ Conference Extended Abstracts on Human Factors in Computing Systems. ACM, 3049285, 1360-1363. http://dx.doi.org/10.1145/3027063.3049285

[17] Elliot Fishman and Christopher Cherry. E-Bikes in the Mainstream: Reviewing a Decade of Research. Transport Reviews 36, 1 (2016), 72-91. http://dx.doi.org/10.1080/01441647.2015.1069907

[18] Richard Byrne Florian Mueller, Josh Andres, Rakesh Patibanda. 2018. Experiencing the Body as Play. In Proceedings of SIGCHI Conference on Human Factors in Computing Systems. 10.1145/3173574.3173784

[19] Akiko Fujise. 2018. Investigation of Practical Compensation Method for Bone Conduction Headphones with a Focus on Spatialization. In Proceedings of Audio Engineering Society Conference: 2018 AES International Conference on Spatial Reproduction-Aesthetics and Science. Audio Engineering Society.

[20] Alberto Gallace and Charles Spence. The Cognitive and Neural Correlates of Tactile Memory. Psychological bulletin 135, 3 (2009), 380. http://dx.doi.org/10.1037/a0015325

[21] Kathrin M Gerling, Conor Linehan, Ben Kirman, Michael R Kalyn, Adam B Evans and Kieran C Hicks. Creating Wheelchair-Controlled Video Games: Challenges and Opportunities When Involving Young People with Mobility Impairments and Game Design Experts. International Journal of Human-Computer Studies 94 (2016), 64-73. https://doi.org/10.1016/j.ijhcs.2015.08.009

[22] Martine Hausberger, Hélène Roche, Séverine Henry and E Kathalijne Visser. A Review of the HumanHorse Relationship. Applied animal behaviour science 109, 1 (2008), 1-24. https://doi.org/10.1016/j.applanim.2007.04.015 
[23] Chandrika Jayant, Christine Acuario, William Johnson, Janet Hollier and Richard Ladner. 2010. VBraille: Haptic Braille Perception Using a TouchScreen and Vibration on Mobile Phones. In Proceedings of the 12th international ACM SIGACCESS conference on Computers and accessibility. ACM, 295-296. $10.1145 / 1878803.1878878$

[24] M Johnson and G Rose. Report on Safety Implications of E-Bikes. 2015. Victoria, Australia: Royal Automobile Club of Victoria (RACV).

[25] Marilyn Johnson, Judith Charlton, Jennifer Oxley and Stuart Newstead. Why Do Cyclists Infringe at Red Lights? An Investigation of Australian Cyclists' Reasons for Red Light Infringement. Journal of Accident Analysis \& Prevention 50 (2013), 840-847. 10.1016/j.aap.2012.07.008

[26] Paul G Keil. Human-Sheepdog Distributed Cognitive Systems: An Analysis of Interspecies Cognitive Scaffolding in a Sheepdog Trial. Journal of Cognition and Culture 15, 5 (2015), 508-529. https://doi.org/10.1163/15685373-12342163

[27] Brian Casey Langford, Jiaoli Chen and Christopher R Cherry. Risky Riding: Naturalistic Methods Comparing Safety Behavior from Conventional Bicycle Riders and Electric Bike Riders. Accident Analysis \& Prevention 82 (2015), 220-226. https://doi.org/10.1016/j.aap.2015.05.016

[28] SpeedX Leopard. 2016. Speedx Aero Leopard. https://www.kickstarter.com/projects/speedx/speedxleopard-the-first-ever-smart-aero-roadbike?ref=most_funded.

[29] PR Lowrie. Scats, Sydney Co-Ordinated Adaptive Traffic System: A Traffic Responsive Method of Controlling Urban Traffic (1990).

[30] Joe Marshall, Alexandru Dancu and Florian Floyd Mueller. 2016. Interaction in Motion: Designing Truly Mobile Interaction. In Proceedings of the 2016 ACM Conference on Designing Interactive Systems. ACM, 215-228. 10.1145/2901790.2901844

[31] K McAuliffe and A Thornton. The Psychology of Cooperation in Animals: An Ecological Approach. Journal of Zoology 295, 1 (2015), 23-35.

10.1111/jzo.12204

[32] Katina Michael. Science Fiction Is Full of Bots That Hurt People:... But These Bots Are Here Now. IEEE Consumer Electronics Magazine 5, 4 (2016), 112-117. 10.1109/MCE.2016.2590218

[33] Falco Motors. 2014. Falco Electric Wheel Heartbeat. https://www.fastcompany.com/3035452/this-electricbike-is-controlled-by-your-heartbeat-for-the-perfectworkout.

[34] Prakash Murugesan, Norman J Weigert, Mark A Manickaraj and Jarvis Chau. 2017. Automated EAssist Adjustment to Prevent User Perspiration. https://patents.google.com/patent/US9828060B2/en.
[35] Sz Naderi, Ádam Miklósi, Antal Dóka and Vilmos Csányi. Co-Operative Interactions between Blind Persons and Their Dogs. Applied Animal Behaviour Science 74, 1 (2001), 59-80. https://doi.org/10.1016/S0168-1591(01)00152-6

[36] Donald A Norman. The 'Problem'with Automation: Inappropriate Feedback and Interaction, Not 'overAutomation'. Phil. Trans. R. Soc. Lond. B 327, 1241 (1990), 585-593. 10.1098/rstb.1990.0101

[37] Marianna Obrist, Sue Ann Seah and Sriram Subramanian. 2013. Talking About Tactile Experiences. In Proceedings of the SIGCHI Conference on Human Factors in Computing Systems. ACM, 1659-1668. 10.1145/2470654.2466220

[38] Mariella Pazzaglia and Marco Molinari. The Embodiment of Assistive Devices - from Wheelchair to Exoskeleton. Physics of life reviews 16 (2016), 163 175. 10.1016/j.plrev.2015.11.006

[39] Tibor Petzoldt, Katja Schleinitz, Sarah Heilmann and Tina Gehlert. Traffic Conflicts and Their Contextual Factors When Riding Conventional Vs. Electric Bicycles. Transportation research part F: traffic psychology and behaviour 46 (2017), 477-490. https://doi.org/10.1016/j.trf.2016.06.010

[40] Paul A Plazier, Gerd Weitkamp and Agnes E van den Berg. "Cycling Was Never So Easy!" an Analysis of E-Bike Commuters' Motives, Travel Behaviour and Experiences Using Gps-Tracking and Interviews. Journal of transport geography 65 (2017), 25-34. https://doi.org/10.1016/j.jtrangeo.2017.09.017

[41] IBM Research. Trusting AI - The new frontiers of AI, Selected IBM Research AI publications from 2018. https://www.research.ibm.com/artificialintelligence/publications/2018/trusting-ai/

[42] Duncan Rowland, Martin Flintham, Leif Oppermann, Joe Marshall, Alan Chamberlain, Boriana Koleva, Steve Benford and Citlali Perez. 2009. Ubikequitous Computing: Designing Interactive Experiences for Cyclists. In Proceedings of 11 th International Conference on Human-Computer Interaction with Mobile Devices and Services. ACM, 1613886, 1-11. http://dx.doi.org/10.1145/1613858.1613886

[43] Esther Salmeron-Manzano and Francisco ManzanoAgugliaro. The Electric Bicycle: Worldwide Research Trends. Energies 11, 7 (2018), 1894.

[44] Iulian Vlad Serban, Alessandro Sordoni, Yoshua Bengio, Aaron C Courville and Joelle Pineau. 2016. Building End-to-End Dialogue Systems Using Generative Hierarchical Neural Network Models. In Proceedings of AAAI. arXiv:1507.04808.

[45] Keng Siau and Weiyu Wang. Building Trust in Artificial Intelligence, Machine Learning, and Robotics. Cutter Business Technology Journal 31, 2 (2018), 47-53. 
[46] Superhuman Sports. 2018. "Super Sports" Re-Invent Sports with Modern Technology. https://superhumansports.org/.

[47] Shaun Sweeney, Rodrigo Ordonez-Hurtado, Francesco Pilla, Giovanni Russo, David Timoney and Robert Shorten. Cyberphysics, Pollution Mitigation, and Pedelecs. arXiv preprint arXiv:1706.00646 (2017).

[48] P Vermesch. L'entretien D'explicitation En Formation Initiale Et En Formation Continue. Collection pédagogies. ESF éditeur (1994).

[49] Liam Richard West. Strava: Challenge Yourself to Greater Heights in Physical Activity/Cycling and Running. British journal of sports medicine 49, 15 (2015), 1024-1024. http://dx.doi.org/10.1136/bjsports2015-094899
[50] Jason Wuertz, Sultan A Alharthi, William A Hamilton, Scott Bateman, Carl Gutwin, Anthony Tang, Zachary Toups and Jessica Hammer. 2018. A Design Framework for Awareness Cues in Distributed Multiplayer Games. In Proceedings of the 2018 CHI Conference on Human Factors in Computing Systems. ACM, 243. 10.1145/3173574.3173817

[51] Hongtai Yang, Xiaohan Liu, Fan Su, Christopher Cherry, Yugang Liu and Yanlai Li. Predicting E-Bike Users' Intention to Run the Red Light: An Application and Extension of the Theory of Planned Behavior. Transportation research part F: traffic psychology and behaviour 58 (2018), 282-291. https://doi.org/10.1016/j.trf.2018.05.027

[52] Yiqi Zhang and Changxu Wu. The Effects of Sunshields on Red Light Running Behavior of Cyclists and Electric Bike Riders. Accident Analysis \& Prevention 52 (2013), 210-218.

10.1016/j.aap.2012.12.032 